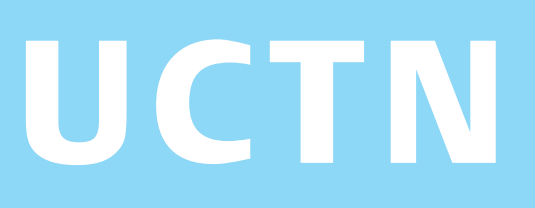

\title{
Extracorporeal shockwave lithotripsy for renal calculi: an unusual cause of common bile duct stricture
}

Pancreatic and hepatobiliary complications due to extracorporeal shockwave lithotripsy (ESWL) treatment for renal calculi are very rare [1]. ESWL-related biliary stricture mimicking malignancy has not been reported to date.

A 50-year-old white man with recent-onset painless jaundice underwent endoscopic retrograde cholangiopancreatography (ERCP). One year before he had been diagnosed with bilateral renal calculi and these were treated on the right side with ESWL (three sessions, 3000 shocks per session, 14-26 kV). His last ESWL session had taken place 2 months prior to the onset of jaundice. His laboratory results showed a cholestatic liver pattern and elevated lipase (136 U/1, normal range 7 $60 \mathrm{U} / \mathrm{l})$. The serum calcium, amylase, carcino-embryonic antigen, and CA 19-9 levels were all normal.

Magnetic resonance cholangiopancreatography showed a focal mid- to distal common bile duct stricture and inflammatory changes in the part of the pancreas adjacent to the duodenum. ERCP showed a $15-\mathrm{mm}$ biliary stricture at the level of the cystic duct, with upstream dilatation of the biliary tree (Figure $\mathbf{1}$ ). The pancreatogram was normal. An exploratory laparatomy was performed, when fibrous reaction was noted around the porta. The common bile duct appeared strictured and it was resected, along with the gallbladder and hilar tissue, with a roux-en-Y hepaticojejunostomy. Histological examination revealed chronic inflammation around the bile ducts (Figure 2 ), and marked xanthomatous and focal granulomatous inflammation in the periductal adventitial soft tissue (Figure 3,4).

In our patient, the time course between ESWL therapy and the onset of jaundice, in the absence of a known cause of a benign/inflammatory bile duct stricture, suggests a possible cause and effect relationship between the ESWL treatment for renal calculus and the development of an inflammatory common bile duct stricture.

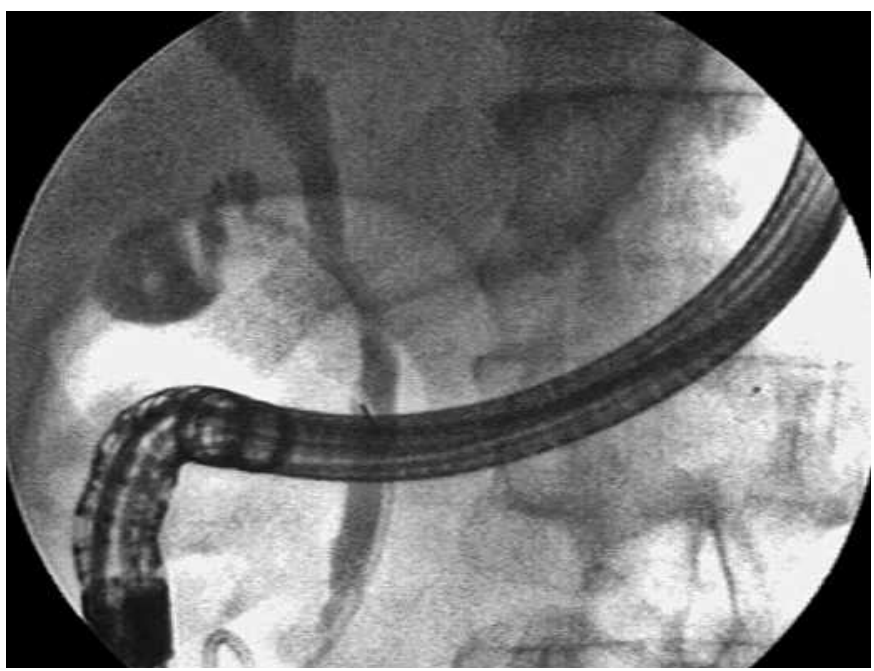

Figure 1 Endoscopic cholangiopancreatographic image showing a biliary stricture.

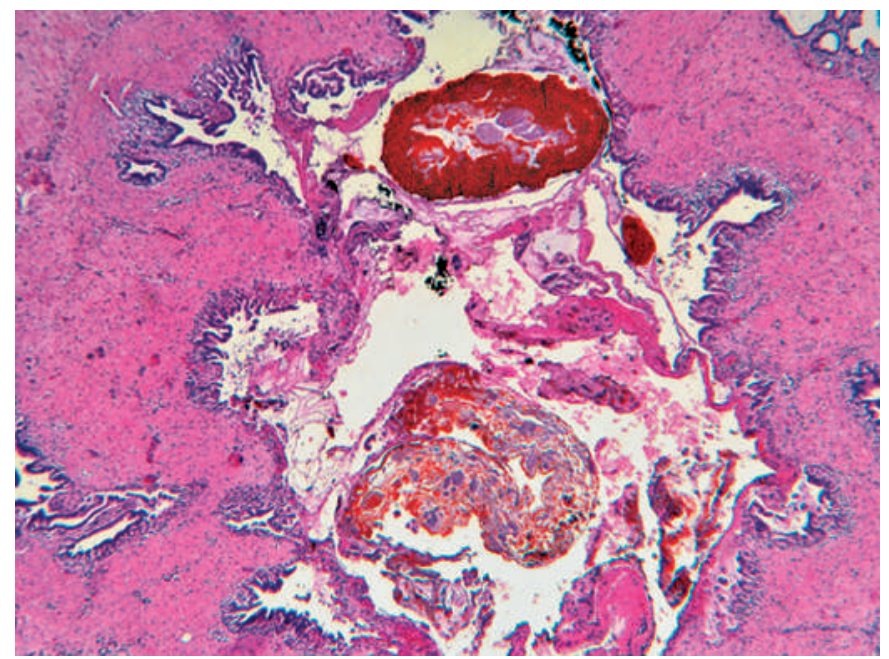

Figure 2 Histological view showing chronic inflammation around the common bile duct (hematoxylin and eosin [H \& E] stain, original magnification $\times 40$ ).

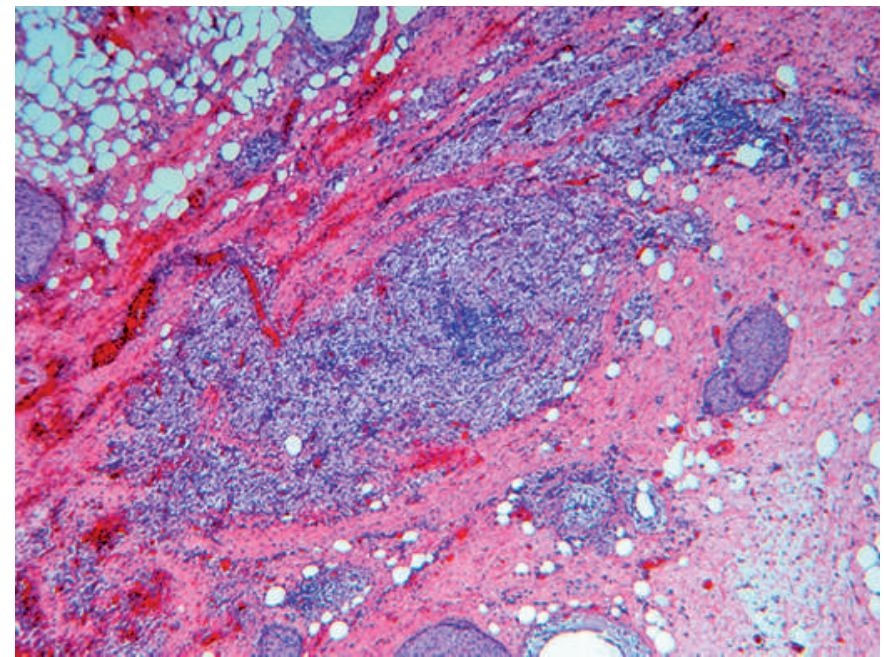

Figure 3 Histological view showing periductal adventitial soft tissue with xanthomatous inflammation with numerous foamy histiocytes (H\&E stain, magnification $\times 40)$. 


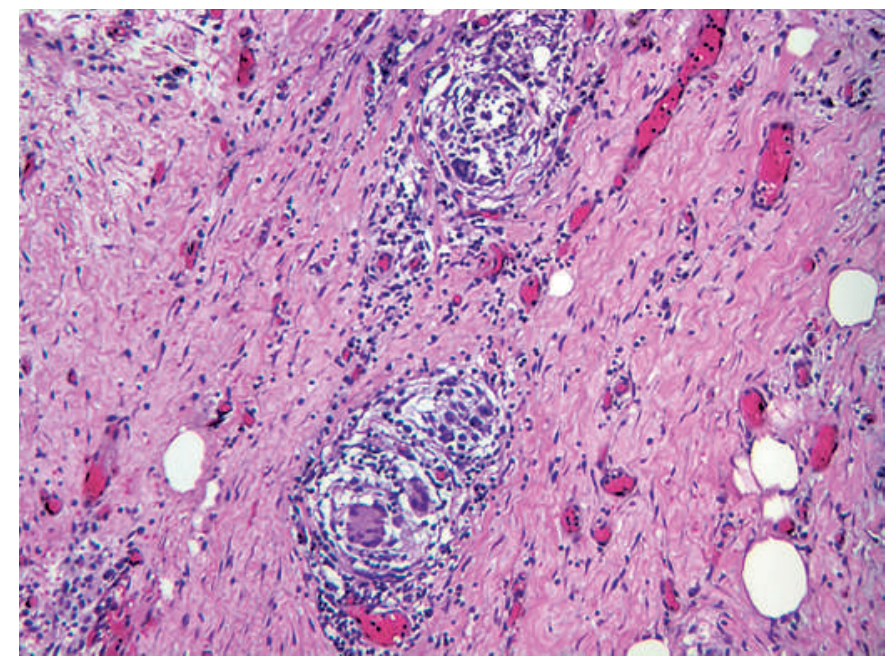

Figure 4 Histological view of an area of granulomatous inflammation with occasional histiocytic giant cells in the periductal adventitial soft tissue (H\&E stain, magnification $\times 200$ ).

Cavitation and microbubble formation is the suggested mechanism for shockwave-induced injury of biological tissues $[2,3]$. The number of shocks delivered, patient position, and inaccurate targeting may also be factors in the development of adverse gastrointestinal effects [1], although these variables did not account for the ESWL-related bile duct injury in our patient.

Endoscopy_UCTN_Code_CCL_1AZ_2AZ

\section{S. K. Ahlawat ${ }^{1}$, T. Fishbein ${ }^{2}$, F. H. Al-Kawas ${ }^{1}$}

${ }^{1}$ Division of Gastroenterology, Georgetown University Hospital, Washington DC, USA

2 Department of Surgery, Georgetown University Hospital, Washington DC, USA.

\section{References}

${ }^{1}$ Maker V, Layke J. Gastrointestinal injury secondary to extracorporeal shock wave lithotripsy: a review of the literature since its inception. J Am Coll Surg 2004; 198: 128-135

${ }^{2}$ Brody JM, Siebert WF, Cattau EL et al. Detection of tissue injury after extracorporeal shockwave lithotripsy of gall stones. J Clin Gastroenterol 1991; 13: 348-352

${ }^{3}$ Forer LE, Davros WJ, Goldberg J et al. Hepatic cavitation: a marker for transient hepatocellular injury during biliary lithotripsy. Dig Dis Sci 1992; 37: 1510-1516

\section{Corresponding author}

\section{F. H. Al-Kawas, M.D.}

Division of Gastroenterology, Department of Medicine Georgetown University Hospital 3800 Reservoir Road NW Washington DC 20007

USA

Fax: $\quad+1-202-444-0417$

Email: alkawasf@gunet. georgetown.edu 